\title{
O SIGNO DA PARTICIPAÇÃO: MUSEU E EDUCAÇÃO NA PERSPECTIVA DA SOCIOMUSEOLOGIA
}

The sign of participation: museum and education from the perspective of Sociomuseology

El signo de la participación: museo y educación desde la perspectiva de la Sociomuseologia

Juliana Maria de Siqueira ${ }^{1}$

\section{RESUMO}

O artigo aborda a consolidação da Museologia como campo disciplinar transversal das ciências sociais, num contexto histórico em que se atribui uma função social aos museus e do qual deriva uma nova visão museológica, a Sociomuseologia. Sob esse prisma, exploramos os desafios para a consolidação teórico-prática da educação museal, a partir da análise de uma experiência concreta, desenvolvida no Museu da Imagem e do Som de Campinas, entre os anos de 2007 e 2012, nos bairros Gênesis, Jardim Nilópolis e São Quirino, Leste da cidade.

Palavras-chave: Educação museal, participação, sociomuseologia.

\section{ABSTRACT}

This article addresses the consolidation of Museology as a cross-disciplinary field of social sciences, in a historical context that assigns a social role to museums and gives birth to a new museological conception: Sociomuseology. From this perspective, it explores the challenges to theoretical and practical consolidation of museum education, departing from the analysis of a concrete experience, performed by Campinas Museum of Image and Sound, SP, Brazil, between 2007 and 2012, in the neighborhoods of Gênesis, JardimNilópolis and São Quirino.

Keywords: Museum education, participation, sociomuseology.

\section{RESUMEN}

Este artículo aborda la consolidación de la Museologia como campo interdisciplinario de las ciencias sociales, en un contexto histórico donde se confiere una función social a los museos y del cual deriva una nueva visión museológica, la Sociomuseologia. Desde esta perspectiva, exploramos los desafíos a la consolidación teórica y práctica de la educación museal,basado en el análisis de una experiencia concreta, desarrollada en Museo de la Imagen y Sonido de Campinas, SP, Brasil, entre los años de 2007 y 2012, en la región Leste de la ciudad.

Palabras clave: Educación museal,participación, sociomuseologia.

\footnotetext{
${ }^{1}$ Especialista Cultural no Museu da Imagem e do Som de Campinas. Graduada em Comunicação Social pela UFMG (1996), MBA em Marketing de Serviços pela ESPM (2003), Especialista em Multimeios pela Unicamp (2001) e Mestre em Ciências da Comunicação pela ECA-USP (2009). E-mail: ju.de.siqueira@ gmail.com.
} 


\section{Introdução}

O presente artigo é fruto da necessidade de sistematizar e analisar, teoricamente, o trabalho educativo desenvolvido no Museu da Imagem e do Som de Campinas (MIS), instigada pelas leituras e debates a respeito do patrimônio e das transformações em sua definição. A discussão vem contextualizar o terreno no qual se fundamentamessas ações, a Sociomuseologia, e identificar os requisitos teóricos e metodológicos que ela desenha para a Educação Museal. Reconhecendo que se trata de uma área de estudos recente, não completamente estruturada, busca-se levantar campos acadêmicos, teorias e conceitos que, sendo capazes de dialogar satisfatoriamente com a Sociomuseologia, possam fornecer categorias-chave para produção e avaliação de ações educativas em museus. $\mathrm{O}$ exame de uma situação concreta, desenvolvida pelo MIS entre 2007 e 2012, na região dos bairros São Quirino, Jardim Nilópolis e Gênesis, permitirá compreender a necessidade de deslocar práticas e processos museais tradicionais para situar, no centro do fazer, a participação social e o desenvolvimento local, por meio da produção e gestão do patrimônio de uma comunidade.

\section{Museus na contemporaneidade: a museologia social e seus princípios}

Embora a existência dos museus - como instituições dedicadas à preservação do patrimônio público nacional - remonte ao início do período contemporâneo (JULIÃO, 2006), foi apenas nos anos 1990 que a Museologia consolidou-se como um campo disciplinar específico das ciências sociais (SCHEINER, 2012). A trajetória dessa estruturação encontra seus antecedentes em fins do século XIX, com a profissionalização do trabalho do museu, o desenvolvimento de abordagens científicas para a conservação (GRANATO \& CAMPOS, 2013), a criação das primeiras associações profissionais, o surgimento de publicações e manuais e dos programas pioneiros de formação museográfica. (PEREIRA, 2004 e 2010) Até então, tratavase de compreender os problemas da preservação de coleções e aprimorar os processos internos a ela pertinentes - perspectiva que caracteriza uma abordagem tradicional dos museus. $\mathrm{Na}$ primeira metade do século XX, as atenções voltaram-se para a democratização da instituição, entendida como sua abertura ao público em geral e o desenvolvimento de seu papel educativo, ainda que numa perspectiva de elevação cultural dos visitantes. (PEREIRA, 2004)

A criação do Comitê Internacional de Museus (ICOM), em 1946, desempenhou importante papel na clivagem desse processo, por congregar instituições e profissionais e promover amplo debate em seus encontros e conferências, ensejando a emergência de uma nova- 
noção do trabalho museológico, com foco na sociedade e seu desenvolvimento e ênfase nas dimensões locais/ regionais do patrimônio e na participação comunitária. Merecem destaque, como marcos que contribuem para a formulação dessa abordagem social, o Seminário Regional da Unesco sobre a Função Educativa dos Museus (Rio de Janeiro, 1958), a $8^{\text {a }}$ e a $9^{\text {a }}$ Conferências Gerais do ICOM, realizadas em Munique (1968) e Paris/Grenoble (1971), a MesaRedonda de Santiago do Chile (1972), o I Atelier Internacional da NovaMuseologia, ocorrido em Quebec, o Seminário de Oaxtepec (ambos em 1984) e o Seminário de Caracas (1992). Não nos cabe reconstituir o percurso pelo qual a concepção de museu transforma-se gradativamente, dando origem ao movimento da Nova Museologia, considerando-se que o argumento já foi satisfatoriamente explorado por Primo (1999), Santos (2002), Pereira (2004, 2010), Scheiner (2012) e outros. Mas é preciso ressaltar que não se trata, aqui, de um movimento de cúpula alheio às bases sociais e que as mobilizações de caráter artístico-cultural desde o final dos anos 60 foram cruciais na revisão da relação museu-sociedade (SANTOS, 2002).

Ainda no âmbito do ICOM, devemos ressaltar a criação, em 1976, do Comitê Internacional para a Museologia (ICOFOM), reunindo os principais estudiosos que, desde os anos 60, dedicavam-se ao debate sobre o campo museológico e estimulando a elaboração de documentos de trabalho que fundamentam a museologia não apenas como atividade prática, mas como ciência com objeto e metodologia próprios. Segundo Scheiner (2012:16), “ao final dos anos 1980, já se confirmava a existência de uma teoria da Museologia e definia-se para ela um lugar de fala no universo acadêmico". Os latino-americanos não estavam ausentes do movimento e, sobretudo a partir dos anos 1990, forneceram subsídios ao desenvolvimento da Teoria Museológica. Naquela década de intensa produção científica, formularam-se os termos e conceitos básicos do campo, inaugurando-se programas de formação universitária e revisando-se a estrutura curricular dos já existentes. Em Portugal, Mário Moutinho (1993) concebeu a Museologia Social como o esforço de adequação das estruturas museológicas aos condicionamentos da sociedade contemporânea, definindo-a, mais tarde (2007), como uma área multidisciplinar de ensino, investigação e atuação que articula a Museologia às Ciências Humanas e a reconhece como recurso para o desenvolvimento sustentável da humanidade, baseado na igualdade de oportunidades e inclusão social e econômica.

Na virada do milênio, a Museologia estaria plenamente consolidada como transdisciplina dedicada à administração da memória e do uso da herança patrimonial (MENESES apud BRUNO, 1996), e ao estudo da relação específica entre o homem e a realidade, da qual alguns objetos são deslocados (musealizados) para serem preservados e utilizados com fins de conhecimento, sendo-lhes atribuídas novas significações. Nessa relação, o real é tomado em 
sua totalidade material e imaterial, natural e cultural, e o passado posto a serviço do presente. Bruno (1996) e Santos (1996) reconstituem o percurso histórico pelo qual as definições do campo e do objeto da Museologia foram se configurando e é imperativo reconhecer ali a influência da Nova Museologia - a princípio, uma via alternativa às práticas e concepções tradicionais. Pereira (2004) ressalta que esse reconhecimento, ou mesmo a convergência entre as duas correntes museológicas não foi imediato ou isento de conflitos e demonstra que apenas a partir de Caracas (1992), iniciou-se um esforço em direção ao consenso e à compreensão partilhada sobre a substância e finalidade do campo.

Embora, no debate teórico, haja um empenho para se integrar a vertente social ao campo geral da Museologia, esmaecendo os contrastes entre ambos, bem como discursos que esbatem as resistências e conflitos históricos (cf. críticas de PEREIRA, 2004), e se preconize que mesmo museus tradicionais tenham importância para as comunidades a que servem e possam atuar segundo os pressupostos do museu integral (SCHEINER, 2012), é necessário adotar postura criteriosa na interpretação e aplicação dos princípios museológicos pelos quais se opta. Santos (2008) evidenciaas armadilhas ocultas no apagamento de fronteiras e definições. Muitos discursos que assimilaram o conceito de desenvolvimento, por exemplo, trazem abordagens que vão dos matizes mais revolucionários aos conservadores, passando pelos meramente adaptativos. Moutinho (apud SANTOS, 2008) também alerta que não é fácil para as instituições abrirem mão de seu poder, o que gera ambiguidades e confrontos, muitas vezes, difíceis de solucionar, e cria domínios que permanecem insensíveis às mudanças sociais.

A distinção entre orientações do pensamento e da prática museológica e o posicionamento consciente no campo da Sociomuseologia - embora não constituam valor per se, imperativo, tampouco panaceia (SANTOS, 2002) - significam a assunção de uma postura ético-política libertária e implicam a adoção de pressupostos epistemológicos, teóricos e metodológicos coerentes - ainda que, ou, por isso mesmo, plurais. Considerando que os profissionais de museus lidam em seu cotidiano com realidades complexas e contraditórias às quais devem se adaptar, e reconhecendo que a Sociomuseologia não prescreve receitas ou modelo ideal, mas incentiva a criação diversa, dentro do possível (SANTOS, 2002), seus princípios serviriam de parâmetros para a construção e avaliação de políticas, programas e projetos museológicos. Sob seu prisma, pois, emergem as seguintes categorias de produção e leitura da realidade museal: (Cf. MOUTINHO, 2007; SANTOS, 2002 e SANTOS, 2008)

O museu integral/ integrado à comunidade- $\mathrm{O}$ museu é agente social e político. Não mais coletor passivo de objetos a organizar em tipologias, ele interfere na totalidade do meio social ao identificar e pautar, com a comunidade, temas de seu interesse atual, evidenci- 
ando problemas e potencialidades de solução e atuando como instrumento dinâmico de mudança social. A comunidade, aqui, é definida por dois critérios básicos: interação social e senso de pertencimento (VARINE apud SANTOS, 2008).

\section{O desenvolvimento comunitário/ local como objetivo da ação museológica - A} incorporação da noção de desenvolvimento, emersa das esferas políticas e econômicas, (PEREIRA, 2009) aos debates a respeito de museus e patrimônio, exigiu esforços para conciliá-la com a atitude de preservação. Sinteticamente, os ajustes dizem respeito à inclusão das comunidades nos trabalhos de preservação e interpretação do patrimônio e à compreensão de que estas não são um fim em si mesmas, mas um meio, e que seu foco não deve ser o objeto, mas a significação por meio da qual ele se torna herança, posta a serviço do presente.

A participação como meio de atingir o desenvolvimento - Entendida como cooperação e coprodução de processos museais pela comunidade, desde o debate e a tomada de decisões até a efetiva atuação no trabalho museológico (SANTOS, 2002), ela mobiliza conceitos e práticas como protagonismo cultural e autogestão. Supõe considerar os sujeitos sociais ativos e implica horizontalidade e igualdade entre especialistas do museu e comunidade, que percebe e exerce sua capacidade de auto-organização para gerir seu tempo e seu futuro.

A ação em um território - A prática museal é baseada em ações sobre o território de uma comunidade e a totalidade do seu patrimônio, não na formação de coleções. Isso permite interpretar as relações do ser humano com seu ambiente e a influência da herança cultural e natural na identidade dos indivíduos e grupos. (SANTOS, 2002)

O patrimônio global (natural, cultural, material, imaterial)- Meio fundamental de desenvolvimento, deve ser gerenciado no interesse de todos. A memória coletiva, no museu, é ponto de partida para a transformação da realidade.

A educação libertária - Como apropriação permanente do patrimônio e como socialização da preservação, é a essência mesma do processo museológico.

A dimensão comunicativa - $\mathrm{O}$ museu, como fórum, é ponto de encontro e convivência democrática, plural e diversa, campo vivo de ação/ performance/ agenciamento. Espaço de construção de experiência por meio do diálogo e exercício da comunicação, lugar de reconhecimento e recriação de identidades e culturas de múltiplos grupos humanos.

No Brasil, a atual Política Nacional de Museus (PNM), definida e implementada pelo Ministério da Cultura (MinC) por meio do Instituto Brasileiro de Museus (Ibram), - resultante de amplo processo participativo de consulta à comunidade museal - assume orientação claramente Sociomuseológica. De acordo com o documento convocatório para a discussão da política, lançado em 2003, os museus têm papel fundamental na valorização do patrimônio cultu- 
ral (tomado em perspectiva ampla) como "dispositivo estratégico de aprimoramento dos processos democráticos". Eles são entendidos como "processos a serviço da sociedade e do seu desenvolvimento", "comprometidos com a gestão democrática e participativa”, cujo objetivo é "propiciar a ampliação do campo das possibilidades de construção identitária e a percepção crítica acerca da realidade cultural brasileira" (MINISTÉRIO da Cultura, 2003:8). A respeito da reverberação dessas propostas no II e III Fóruns Nacionais de Museus, ocorridos em 2006 e 2008, o MinC declarou que seu foco de atenção foram as "novas experiências museais e a centralidade da museologia social”(MINISTÉRIO da Cultura, 2010: 12).

Desnecessário sublinhar em que contexto político irrompe o processo de construção da PNM. Mas, vale à pena relembrar os desafios sociais a que ela se dirige, e em cuja direção lança os museus, como agentes estratégicos no seu enfrentamento: superação da histórica desigualdade social e dos quadros de extrema pobreza, reconhecimento da pluralidade cultural brasileira, promoção dos direitos humanos e de políticas afirmativas de combate ao preconceito e de valorização das identidades das minorias (em termos de poder) étnicas, de gênero e orientação sexual, solução dos problemas decorrentes do processo de urbanização acelerada e sem planejamento, melhoria do nível educacional, oferta de oportunidades aos jovens para construção de projetos de vida, proteção à biodiversidade, fortalecimento da democracia participativa, entre outros. Ao se reconhecer a prioridade dessas questões e a capacidade dos museus contribuírem para as transformações necessárias,optando pelo engajamento nessa perspectiva e assumindo os compromissos sociais, éticos e políticos nela implicados, deve-se levar em conta que a prática profissional configura-se como exercício de criação coletiva, que exige permanente formação e reflexividade. É preciso buscar, na práxis, sistematizar as experiências concretas desenvolvidas e confrontá-las criticamente a categorias teóricas coerentes com esta abordagem. Desse exame crítico, podem resultar contribuições ao avanço do campo museológico, tanto na sua epistemologia quanto na sua prática. Particularmente, interessa, neste artigo, explorar algumas implicações desses pressupostos sobre a estruturação teóricometodológica da Educação Museal.

\section{Desafios para a estruturação teórico-metodológica da educação museal}

A relação entre museus e educação é bastante longa, visto que, desde seus mitos de origem, o mouseiom guardava uma ligação com o saber. Studart (2004) propõe compreender essa relação, que ela denomina pedagogia museal, a partir de três elementos de igual importância: a função educativa dos museus, isto é, aquilo que lhe compete como instituição (o 
porquê e para quê se educa); as ações educativas efetivamente empreendidas; e a Educação Museal ou Patrimonial, área do conhecimento da Museologia que fundamenta a prática.

Vimos que a função educativa é elemento crucial na abordagem Sociomuseológica e, nesse sentido, encontra-se suficientemente fundamentada no campo teórico. Mas, a discussão a seu respeito antecede em muito ao advento da Nova Museologia. Uma visão histórica bastante aprofundada sobre as transformações no seu entendimento é construída por Pereira (2010), que identifica e discute cinco dimensões que a constituem: a educacional contemplativa, a cívica, a democrática, a escolarizada e a socioeducativa.

É no terreno das ações concretas e seus fundamentos que falta mais ampla discussão. Em 2006, Cabral (2007) realizou levantamento junto a 192 dos quase dois mil museus brasileiros que havia então (hoje são mais de três mil segundo o Ibram) e constatou que $82 \%$ promoviam algum tipo de ação educativa (a maioria, visitas escolares e do público em geral). Grande parte dessas instituições estava localizada nas capitais dos estados e menos de 60\% realizavam avaliações sobre suas ações. Segundo dados recentes do Cadastro Nacional de Museus (IBRAM, 2011), apenas 48,1\% dos museus possuem setor educativo constituído; $80,6 \%$ promovem visitas guiadas, sendo a maior parte $(76,4 \%)$ realizada com agendamento, e pouco mais da metade $(50,2 \%)$ realizam atividades sistemáticas com a comunidade. Embora apresentem indícios sobre o tipo de ações empreendidas, as pesquisas não fornecem dados qualitativos sobre como se desempenham essas atividades, seu caráter e fundamentos. Ainda hoje, investigações dessa natureza apresentam escopos limitados em relação à abrangência geográfica e às tipologias de museus, não sendo possível compreender o "estado da arte" das ações educativas no Brasil. Estudiosos apontam queapenas recentemente a atividade obteve valorização e, por muito tempo, enfrentou circunstâncias adversas como formação não específica de mediadores, persistência do preconceito, insuficiência de publicações e divulgação sobre o tema e descompasso entre discursos e práticas (BARBOSA, 2009 e LEITE, 2005).

Mas, se o que se produz no dia-a-dia de boa parte dos museus permanece distante de reflexão e exame crítico, constata-seque ações educativas de destaque, dos mais bem estruturados museus ou dos ecomuseuscom história consolidada e vínculos com universidades, estão fartamente documentadas e relatadas. Também a criação da Rede de Educadores em Museus (REM), no Rio de Janeiro, em 2003, sob o estímulo do Ibram, foi impulso valioso para a organização dos profissionais e o intercâmbio de experiências, a formação continuada, o mapeamento de ações e o desenvolvimento de pesquisas e parcerias. A REM multiplicou-se por outros estados e Distrito Federal, em caráter independente, mas com apoio do Ibram: Distrito Federal, Ceará e Pernambuco (2008), Mato Grosso e Paraíba (2009), Rio Grande do Sul, San- 
ta Catarina e Goiás (2010) e Bahia (2011). Na cidade de São Paulo, em 2013, foi lançado, pelo Museu da Língua Portuguesa, o Centro de Referência de Educação em Museus.

Aos poucos, foi-se desenhando a necessidade de se criar uma política pública para o setor. Em 2005, o IPHAN promoveu o primeiro Encontro Nacional de Educação Patrimonial, em São Cristóvão, SE. Segundo Lima (2008), o evento proporcionou uma síntese do processo de desenvolvimento de ações educativas. Outro momento importante, segundo a pesquisadora, foi a realização do I Fórum Latino-Americano de Educação Patrimonial, pelo Laboratório de Educação Patrimonial e Arqueologia da Universidade Federal de Pelotas e o Instituto de Memória e Patrimônio, durante a Semana Nacional de Museus, de 2008. Ela concluiu, com base em seus levantamentos, que era urgente a necessidade de avaliação dos objetivos e pressupostos das atividades educativas museais em curso no Brasil, sendo preocupante o seu quadro. Em 2010, o I Encontro de Educadores do Instituto Brasileiro de Museus resultou na Carta de Petrópolis, que oferece subsídios para a criação de uma política nacional de Educação Museal. Em julho de 2011, durante o II Encontro Nacional de Educação Patrimonial, ocorrido em Ouro Preto, o tema voltou a ser debatido. Nesses dois últimos, além de questões práticas, como formação de profissionais, legislação, articulação, fomento e gestão, propugnou-se o estabelecimento de amplo debate e aprofundamento de conceitos e referenciais teóricometodológicos, por meio do incentivo à pesquisa acadêmica nos seus diferentes níveis. Em outubro de 2012, o Ibram lançou uma plataforma na Internet de consulta pública visando à construção de diretrizes para as ações educativas e a formulação da Política Nacional de Educação Museal (PNEM). Até abril de 2013, 708 usuários cadastrados, dos quais 263 são profissionais de museus, opinaram em fóruns virtuais sobre nove eixos temáticos. Em janeiro de 2014, foi divulgado o documento preliminar com as propostas apresentadas, para discussão e votação em plenária no Encontro Nacional do PNEM, previsto para novembro deste ano.

No que diz respeito ao estabelecimento da Educação Museal como campo científico, existem trabalhos em três vertentes que se distinguem segundo as tipologias de museus: a arte/educação, a educação patrimonial e a comunicação da ciência (SIQUEIRA, 2010). Embora tais campos possam contribuir significativamente para a presente reflexão, não abordam exclusivamente a educação em museus. Nesse sentido, a primeira investigação que trata da especificidade da constituição da educação museal, baseada na hipótese de que ela possui características que a singularizam e se mantêm à revelia das diferentes tipologias institucionais foi empreendida por Martins (2011), na FE-USP, sob orientação de Martha Marandino.

No entanto, os desafios específicos colocados pela Sociomuseologia à consolidação desse campo permanecem inexplorados. Acima de tudo, faltam estudos que deem conta da 
especificidade da educação museal fundada não nas coleções ou objetos de museus, não nas visitas guiadas e atividades intramuros, mas no encontro com um patrimônio vivo, global de uma comunidade, presente em um território, e que compreenda o museu não como instituição, mas como processo. Evidentemente, as questões relacionadas a esse problema não poderão ser suficientemente debatidas no âmbito deste trabalho, mas é possível verificar aqui a viabilidade de investigá-las a partir do exame de ações educativas empreendidas por um museu, que se caracterizem como práticas de Sociomuseologia. Eis o que se propõe a seguir.

\section{Experimentando conceitos: o MIS Campinas na região do Ribeirão das Anhumas}

Vasconcellos (2012) retrata o processo de criação do MIS Campinas, em 1975, como resultante de forças distintas e conflitantes - de um lado, a atitude colecionista conservadora e a necessidade de preservação dos registros oficiais da Prefeitura e, de outro, a intenção moderna de disseminar a produção e fruição do audiovisual. Assim, na sua prática museológica, desde sempre conviveram elementos da museologia tradicional e da abordagem social. Nessa vertente, enquadram-se diversos programas e projetos desenvolvidos ao longo dos anos, como o cinema de arte e cineclube, a exibição de cinema nas escolas, atividades itinerantes, leitura crítica de TV, história oral e o incentivo à produção do audiovisual pelo cidadão comum.

É dessa linhagem que surgiu, em 2003, o projeto Pedagogia da Imagem. Destinado, inicialmente, à formação de professores para o uso do vídeo em sala de aula, foi gradualmente se expandindo e diversificando seus públicos e atividades. Tornou-se um programa voltado à apropriação crítica e dialógica do audiovisual, baseada em quatro eixos: conhecimento da história e da linguagem; experimentação da criação; formação de circuitos de fruição cultural nas periferias e incentivo à cultura de acervo (SIQUEIRA, 2009). Sempre em transformação, o programa mantém-se fiel aos princípios da educação dialógica de Paulo Freire e à ideia de que o audiovisual é um potente instrumento de libertação, na medida em que, ao dominá-lo, o educando conquista um novo olhar, pelo qual descobre em seu ambiente (o bairro da periferia) sentidos múltiplos, feitos não só de carências, mas também de memórias, saberes e belezas, e em si, a potência para a criação. Esse empowerment é base da transformação social - ou do desenvolvimento, cujas direções e conteúdos são dados pelos sujeitos em formação e não só pelos educadores - que também se educam e aprendem. Em dez anos de atividades, o programa contribuiu para democratizar o perfil de acervos e programações culturais e o estabelecimento de novas relações com públicos que não frequentavam ou desconheciam o museu. 
Foi em 2007 que se iniciou a relaçãodo MIS com a região do ribeirão das Anhumas. No Leste de Campinas, esta compreende os bairros São Quirino, Nilópolis, Novo Horizonte e Cafezinho e, mais especificamente, a Rua Moscou e o núcleo Gênesis, bem à sua margem. Os bairros e núcleos originaram-se do loteamento e sucessivas ocupações da antiga Fazenda São Quirino, a partir dos anos 70, quando a cidade experimentou um crescimento urbano acelerado, recebendo migrantes de várias partes do país. As favelas ali formadas predominantemente por trabalhadores domésticos, da indústria e da construção civil permaneceram por décadas sem regularização e, portanto, ao largo das políticas públicas de infraestrutura e saneamento. Anualmente, os frágeis barracos eram tomados por enchentes, agravando a situação de vulnerabilidade das famílias. Pouco a pouco, a ausência do poder público abriu espaço para a atuação do tráfico de drogas, tornando a região conhecida não apenas pelos baixos índices de desenvolvimento humano, como também pela violência, gerando estigma social.

Em 2007, omuseurecebera em doação acervos e equipamentos resultantes do projeto "Recuperação ambiental, participação e poder público: uma experiência em Campinas" (TORRES e COSTA, 2006) e, como contrapartida, comprometeu-se a produzir exposição e vídeo com os arquivos de áudio e imagem da coleção. Neles, quatro lideranças da Rua Moscou contavam suas memórias de vida e luta. Migrantes, suas lembranças eram marcadas por diferentes relações com o ambiente e outros rios. Histórias de batalhas por direitos sociais, contra injustiças e preconceitos, e saberes profundos sobre o meio ambiente, e como recuperálo por meio da mobilização. Os depoimentos deixavam claro: não estavam eles à margem da sociedade, eram sujeitos ativos em busca de ser mais (FREIRE, 1987). O vídeo resultante, intitulado 3x4: Retratos da vida à margem de um rio foi lançado no MIS, junto com a exposição fotográfica Projeto Anhumas, durante a Semana do Meio Ambiente, na presença da comunidade, que os recebeu com entusiasmo. Em seguida, a mostra percorreu os bairros, sendo exibida entre 2007 e 2008, gerando debates e ações educativas locais. A ação permitiu aos moradores refletir sobre os problemas ambientais da comunidade, ao mesmo tempo em que demonstrava seu potencial de transformação, pela valorização das identidades locais (migrantes, trabalhadores), seus saberes e a história coletiva, simbolizados pelas lideranças.

Durante o evento no MIS, estavam presentes duas professoras da EMEI Recanto da Alegria, localizada noGênesis. Participantes do curso de formação Pedagogia da Imagem, elas se propuseram a atuar, junto ao museu, na integração entre escola e comunidade, abrindo a dinâmica educativa aos saberes e memórias coletivos. Ao longo do ano, conquistou-se o apoio da equipe gestora, com base no princípio básico do projeto político-pedagógico escolar de 
integrar-se ao entorno - palavra que, em si, denuncia o que está de fora. Foi necessário vencer preconceitos, medos e concepções restritas sobre a função da escola infantil.

Superada essa etapa, realizou-se a primeira ação voltada para a comunidade, com o objetivo de promover o aprendizado audiovisual, tendo os moradores como protagonistas, autores das imagens e discursos. Escolheu-se a fotografia como linguagem introdutória. Foi oferecida uma oficina de fotografia digital, à qual acorreram pessoas de 10 a 60 anos, com perfis variados. A metodologia desenvolvida alternava encontros de aprendizado sobre o uso do equipamento e a linguagem, e passeios fotográficos pelo bairro, cujos roteiros e pontos de interesse eram definidos pelos participantes. Durante os percursos, amizades se formavam, histórias e casos eram compartilhados, saberes locais revelados. Ao final, os aprendizes atuaram como curadores da exposição fotográfica, intitulada Recantos, selecionando 40 imagens e criando seus títulos. A abertura à população deu-se na EMEI, em fins de 2008. No ano seguinte, em março, seria inaugurada no MIS, e um vídeo homônimo foi produzido para registro da experiência. Das fotografias produzidas, 700 foram doadas ao acervo do museu, preenchendo duas lacunas: a de registros contemporâneos da periferia da cidade e a do olhar não oficial e não elitizado. Em seguida, a exposição percorreu o bairro, sendo montada nos equipamentos comunitários, da Assistência Social e ONGs dedicadas a crianças e adolescentes.

Em 2009, o objetivo era desenvolver uma oficina de vídeo, mas as diretrizes da Secretaria de Educação exigiram mudança de planos. Por determinação da escola, as professoras deveriam trabalhar exclusivamente em projetos da brinquedoteca escolar. Uma das educadoras deixou o grupo. As possibilidades de trabalho na brinquedoteca eram limitadas e optou-se, então, por transformá-la, incorporando a ela dimensões imateriais - os saberes e memórias sobre brincadeiras, brinquedos, histórias e cantigas de infância, compartilhadas por familiares das crianças e membros da comunidade. O objetivo era produzir e lançar um vídeo e realizar uma oficina em um Dia de Brincadeiras, ao final do ano. Foram identificados colaboradores com a ajuda do Centro de Assistência Social (CRAS) e, com o apoio de estagiários de História e Ciências Sociais da Unicamp, gravaram-se os depoimentos. O vídeo editado - Infância: memórias e brincadeiras - é uma breve síntese do muito que a comunidade apresentou. Bem mais que lembranças de brincadeiras, os depoimentos revelaram concepções sobre a infância, a educação, trabalho infantil e direitos, vestígios de uma cultura popular caipira, em choque e hibridação com a cultura de massa e consumo - elementos extremamente potentes para serem discutidos no âmbito da escola. A exibição do vídeo, ao final do ano, foi realizada na EMEI, em condições precárias. O Dia de Brincadeiras não se realizou e a parceria dava sinais de esgotamento. Nos anos seguintes, 2010 e 2011, o MIS trabalhou com o CRAS, que enviou duas 
profissionais ao curso Pedagogia da Imagem. A comunidade também passava por transformações, com a urbanização promovida pelo Programa de Aceleração do Crescimento (PAC). As concepções e possibilidades de trabalho, no entanto, eram mais limitadas e optou-se, enfim, pela realização de exibições e debates dos vídeos e montagem das exposições disponíveis.

Em 2012, o MIS tentou realizar um novo vídeo com os protagonistas do 3x4. Das quatro personagens, apenas uma senhora cedeu seu depoimento. Foram feitas imagens do bairro e coleta de informações junto à assistente social. Ficou claro que a urbanização interferiu significativamente na dinâmica local. De um lado, valorizando os imóveis próximos e higienizando e padronizando as moradias. De outro, alterando modos de vida e convivência e desarticulando lideranças. Percebeu-se que o processo havia se dado de cima para baixo, sem consideração por aspectos socioculturais e históricos. Em todo caso, o CRAS propôs ao MIS realizar nova oficina fotográfica, com o objetivo de registrar a atual fisionomia do bairro. Um grupo de adolescentes que se profissionalizam em uma ONG da região interessou-se pelo projeto e empregou-se a metodologia anteriormente desenvolvida. A exposição Gênesis: percursos da criação foi inaugurada em 2012 no CRAS, com debate público sobre meio ambiente, as transformações locais e o processo educativo. Em 2013, foi levada ao MIS e aberta na Semana do Meio Ambiente. A experiência demonstrou que, a despeito das dificuldades de articulação, a participação e mobilização em torno do patrimônio global, tendo o audiovisual como instrumento de registro e exercício do protagonismo cultural, é via poderosa para se estimular o desenvolvimento local. Isso porque a comunidade ainda possui problemas a enfrentar, tanto quanto riquezas - ambientais, culturais, materiais e imateriais - a serem exploradas, a fim de se tornarem herança, recurso para o presente. E essa linguagem, tão contemporânea, articula, confronta, confere visibilidade e amplitude aos discursos da população.

Para o MIS, essa trajetória de cinco anos, se não conta a história linear de um caso de sucesso, ensina novas formas de conceber práticas como a identificação, seleção, interpretação, preservação e comunicação do patrimônio. Ao compartilhar a autoria do processo museológico com a comunidade, partindo do pressuposto de que ela possui legitimidade para tal, o museu deixa de ser a instituição pré-existente, enclausurada, e se torna criação viva e singular, como se a ação educativa possibilitasse a atualização de virtualidades e potências latentes, sendo o ato pelo qual, mutuamente, se significam e configuram três faces de uma mesma realidade: comunidade, museu e patrimônio. Mediar, aqui, não é se colocar no meio dessa relação, como especialista que regula e valida sentidos: é abrir fissuras e construir pontes através das quais o outro possa contaminar o museu e transformá-loem novo. Se os gestores das polí- 
ticas públicas compreendessem a força desse ato na busca de soluções para os problemas urbanos, os museus-processo seriam mais frequentemente convocados a dar sua contribuição.

\section{Caminhos a trilhar: a educação museal produzindo um novo museu?}

No bojo do desenvolvimento da Política Nacional Setorial de Museus, a discussão sobre a Educação Museal coloca-se como estratégica. Trata-se de um campo de reflexão e ação social de desenvolvimento recente e que reclama o estabelecimento de fundamentos epistemológicos, teóricos e metodológicos coerentes, conforme evidencia o empenho coletivo para a construção do Plano Nacional de Educação Museal, encabeçado pelo Ibram, em 2013. E, quando contextualizada no campo da Sociomuseologia, exige esforços ainda maiores para o deslocamento de conceitos oriundos da museologia tradicional.

A experiência educativa do MIS Campinas, nesse sentido, foi um laboratório no qual puderam ser testadas algumas dessas possibilidades. Em primeiro lugar, seu ponto de partida não foram as coleções preexistentes de fotos, equipamentos e filmes, tampouco o Palácio que lhe serve como sede. Ao contrário, iniciou-se no encontro com a comunidade, em seu território concreto, os bairros, estabelecendo-se um diálogo cujo foco era revelar seu patrimônioglobal. Nesse deslocamento, o MIS não perdeu sua identidade - ao contrário: buscou integrar sua missão (a preservação do audiovisual) aos objetivos e interesses locais de desenvolvimento por meio das oficinas e mostras.A educação museal, vista como processo de apropriação, ao conjugar a aprendizagem do audiovisual com a criação reflexiva sobre a realidade mesma dos sujeitos envolvidos, configurou-se, pois, libertária, uma vez que resultou na identificaçãoe projeção de potencialidades existentes para a ação. Para que a transformação se torne efetiva, porém, é necessário o envolvimento e a mobilização de inúmeros agentes, quer da comunidade,quer do poder público ou do terceiro setor.Assim, a educação museal, no contexto da Sociomuseologia, não pode ser efetivada de maneira isolada pela instituição, mas na tessitura de redes. Além disso, em cada comunidade ela se dará de maneira diferente. No caso do MIS, na medida em que novos registros eram produzidos (na ação educativa, pelos próprios educandos), a definição mesma de patrimônio audiovisual tornou-se alargada, tanto em termos conceituais (quem o produz/ de que trata/ quais os meios) quanto em termos práticos, pela ampliação e diversificação das coleções do museu. Ao expô-los, lado a lado com os demais, o MIS configura-se como fórum, permitindo novas conexões e interpretações de seu acervo. 
Portanto, ao se assumir o conceito de patrimônio de maneira ampla e diversa, um desafio se impõe, imediatamente, aos museus que se posicionam no campo da Museologia Social: o de recorrer a uma concepção de museu como processo e adotar um modelo museológico menos centrado na instituição e mais afeito à rede e ao fluxo - um museu que se redefina de maneira plural em cada ponto de conexão onde a educação promova a sua apropriação, de acordo com os significados de que o patrimônio ali se reveste. Que o museu assuma essa configuração fluida não depende de sua tipologia, mas da sua capacidade de tecer relações dialógicas, de cogestão e de mediação com as diferentes comunidades que constituem essa rede. Assim, a identidade do museu-processo e sua função/significação social não são dadas pelos seus acervos, mas pela natureza específica das operações por meio das quais se promove, participativamente, o reconhecimento e a salvaguarda do patrimônio de uma comunidade. Aí reside a sua singularidade - seu modo particular de identificar, organizar, contextualizar e reconstruir referências sociais para os elementos culturais, das identidades e memórias coletivas, bem como de colocá-las em diálogo, como fórum, no espaço público.

Nesse caminho, a educação deixa de ser elo final entre funçõesmuseais desempenhadas por especialistas e o público, para tornar-se a essência do museu, criado e apropriado colaborativamente. Deslocam-se, então, práticas e processos museológicos tradicionais, como o inventário, a preservação, a curadoria e a mediação, cuja centralidade não está mais nos objetos, mas nos sujeitos que participam, se desenvolvem e se libertam em comunhão.

\section{Referências bibliográficas}

BARBOSA, Ana Mae; COUTINHO, Rejane Galvão (orgs.). Arteleducação como mediação cultural e social. São Paulo, Editora Unesp, 2009.

BRUNO, Maria Cristina Oliveira. "Museologia: algumas ideias para a sua organização disciplinar”. Cadernos de Sociomuseologia. Lisboa, ULHT, № 9, p. 9-33, 1996.

CABRAL, Magaly. “Avaliação das ações educativas em museus brasileiros". In: NARDI, Emma (ed.). Thinking, evaluating, re-thinking. Roma, Edizioni Franco Angeli, 2007.

FREIRE, Paulo. Pedagogia do oprimido. 17. ed. Rio de Janeiro, Paz e Terra, 1987.

GRANATO, Marcus e CAMPOS, Guadalupe do Nascimento. "Teorias da conservação e desafios relacionados aos acervos científicos". Midas. V. 1, 2013. Disponível em: <http://midas.revues.org/131>. Acesso em 21 jun. 2013.

IBRAM. Museus em números. Brasília, Instituto Brasileiro de Museus, V. 1, 2011. 
JULIÃO, Letícia. "Apontamentos sobre a história do museu". Caderno de diretrizes museológicas. 2. ed. Brasília, Ministério da Cultura/ IPHAN/ DEMU; Belo Horizonte, SEC/ Superintendência de Museus, p. 19-32, 2006.

LEITE, Maria Isabel. "Museus de arte: espaços de educação e cultura". In: LEITE, Maria Isabel; OSTETTO, Luciana Esmeralda. (orgs.) Museu, educação e cultura: encontros de crianças e professores com a arte. Campinas, Papirus, p. 19-54, 2005.

LIMA, Janice Shirley Souza. "Educação Patrimonial: desafios no contexto da Amazônia". Traços: revista do Centro de Ciências Exatas e Tecnologia. Belém, Unama, v. 10, n. 21,p. 147-160, 2008.

MARTINS, Luciana Conrado. A constituição da educação em museus: o funcionamento do dispositivo pedagógico por meio de um estudo comparativo entre museus de artes plásticas, ciências humanas e ciência e tecnologia. Tese (Doutorado em Educação) - Faculdadede Educação da Universidade de São Paulo, 2011.

MINISTÉRIO da Cultura, Instituto Brasileiro de Museus. Carta de Petrópolis. Subsídios para a construção de uma Política Nacional de Educação Museal. Museu Imperial, 28 jun a $1^{\mathrm{o}}$ jul. 2010 .

. Plano Nacional Setorial de Museus-2010-2020. Brasília, MinC/ Ibram, 2010.

MINISTÉRIO da Cultura. Política Nacional de Museus: memória e cidadania. Brasília, MinC, 2003.

MOUTINHO, Mário Canova. "Definição evolutiva de Sociomuseologia". XII Atelier Internacional do MINOM. Lisboa, ULHT, 2007.

. "Sobre o conceito de Museologia Social". Cadernos de Sociomuseologia. Lisboa, Universidade Lusófona de Humanidades e Tecnologias. № 1, 1993.

PEREIRA, Marcele Regina Nogueira. Educação museal. Entre dimensões e funções educativas: a trajetória da $5^{a}$ Seção de Assistência ao Ensino de História Natural do Museu Nacional. Dissertação (Mestrado em Museologia e Patrimônio)- UNI-RIO/ MAST, Programa de Pós-graduação em Museologia e Patrimônio, Rio de Janeiro, 2010.

PEREIRA, Pedro Manuel Figueiredo Cardoso. O patrimônio perante o desenvolvimento.Tese (Doutorado em Museologia) -UniversidadeLusófona de Humanidades e Tecnologias, Lisboa, 2010.

."Preservar e desenvolver em museologia: contributo para o estudo do objeto e do processo museológico”. Cadernos de Sociomuseologia.Lisboa, ULHT, No 34. 2009.

PRIMO, Judite Santos. "Pensar contemporaneamente a museologia". Cadernos de Sociomuseologia. Lisboa,ULHT, No 16, p. 5-38, 1999.

SANTOS, Maria Célia Teixeira de Moura. "Processo museológico e educação: construindo um museu didático-comunitário". Cadernos de Sociomuseologia. Lisboa, ULHT, No 7, p. 99133, 1996. 
. "Reflexões sobre a Nova Museologia". Cadernos de Sociomuseologia.Lisboa, Universidade Lusófona de Humanidades e Tecnologias, Nº 18, p. 93-139,2002.

SANTOS, Paula Assunção dos. "Sociomuseology 2: Museology and community development in the XXI Century”. Cadernos de Sociomuseologia. Lisboa, ULHT, No 29. 2008.

SCHEINER, Tereza C. "Repensando o museu integral: do conceito às práticas". Boletim do Museu Paraense Emílio Goeldi. Ciências Humanas, v. 7, n. 1,p. 15-30, jan-abr. 2012.

SIQUEIRA, Juliana Maria de. Educação museal: cartografias, trilhas e marcos. Trabalho final da disciplina "Sociedade, Conhecimento e Informação", PPGCI-ECA-USP, 27p., 2010.

. "Pedagogia da Imagem: uma abordagem da ação educativa em audiovisual". Congresso Latino-Americano e Caribenho de Arte/Educação: Concepções contemporâneas. V. 1. Belo Horizonte, UFMG, 2009.

STUDART, Denise. "Conceitos educacionais moldando realidades do museu: missão possível! Conferência Internacional do Comitê de Educação e Ação Cultural do ICOM". Oaxaca, México: 2 a 6 de novembro de 2003. Musas:Revista Brasileira de Museus e Museologia. Rio de Janeiro, DEMU/ IPHAN/ MinC,V. 1, No 1, 2004.

TORRES, Roseli; COSTA, Maria Conceição. Recuperação ambiental, participação e poder público: uma experiência em Campinas. Relatório de pesquisa, 2006. Disponível em: <http://www.iac.sp.gov.br/projeto anhumas/relatorio.htm> Acesso em 26 jun. 2013.

VASCONCELLOS, Mirna. MIS - Um museu campineiro brasileiro: sentidos e fragmentos da cidade e do Museu da Imagem e do Som de Campinas. Campinas, Pontes, 2012. 